\title{
Para-aminosalicylic acid-induced hypoglycaemia in a patient with diabetic nephropathy
}

\author{
P. DANDONA \\ M.R.C.P., D.Phil.
}

\author{
E. GREENBURY \\ M.B. B.S.
}

\author{
A. G. BECKETT \\ M.A., B.M., F.R.C.P. \\ Royal Free Hospital, Pond Street, London NW3 2QG
}

\begin{abstract}
Summary
A 62-year-old Indian with diabetic nephropathy controlled with metformin, developed miliary tuberculosis for which he was treated with rifampicin, isoniazid and ethambutol. Soon afterwards he developed cholestatic hepatitis and visual disturbance. Rifampicin and ethambutol were stopped. Streptomycin caused vertigo and had to be stopped. The introduction of para-aminosalicylic acid (PAS) led to hypoglycaemic coma. Metformin was stopped. Hypoglycaemic coma recurred. PAS was stopped and the patient's blood glucose concentrations became normal. Treatment with isoniazid and ethambutol led to total recovery from pulmonary tuberculosis. The induction of hypoglycaemia with PAS in this patient suggests a potential role for PAS in the treatment of diabetes mellitus.
\end{abstract}

\section{Introduction}

Salicylates are known to exert a hypoglycaemic effect (Reid, Macdougall and Andrewes, 1957; Reid and Lightbody, 1959). A number of related compounds including aspirin have been investigated for their relative efficacy in lowering blood glucose concentrations. There is, however, no report suggesting that para-aminosalicylic acid (PAS) may exert a hypoglycaemic effect either in the human or in experimental animals. A patient is now described who developed hypoglycaemic coma twice while on treatment with PAS.

\section{Case report}

A 62-year-old Indian with long-standing diabetes mellitus, nephropathy, retinopathy and a mild residual hemiparesis from a previous stroke was admitted with fever, sweats and non-productive cough of one month's duration. His chest X-ray showed diffuse reticulo-nodular shadowing. His $\mathrm{Hb}$ was $12.1 \mathrm{~g} / \mathrm{dl}$ with WCL $8.9 \times 10^{9} / 1$, his ESR was $20 \mathrm{~mm}$ in 1st hour. Blood urea was $10 \mathrm{mmol} / \mathrm{l}$ and the electrolytes were normal; serum creatinine was $180 \mu \mathrm{mol} / 1$ and the creatinine clearance was 40 $\mathrm{ml} / \mathrm{min}$. Six sputum samples and 3 gastric washings did not show any mycobacteria. Liver biopsy showed multiple granulomata but no caseation or acid fast bacilli. Mantoux test $(1: 100)$ was negative. Despite this, the patient was started on rifampicin $600 \mathrm{mg}$, isoniazid $300 \mathrm{mg}$, ethambutol $1.2 \mathrm{~g}$ and pyridoxine $20 \mathrm{mg}$ daily. The pyrexia and night sweats subsided in 7 days. On the 14th day of treatment, the patient developed pruritus and the urine contained bilirubin and urobilinogen. Two days later he became icteric and had a conjugated hyperbilirubinaemia $(90 \mu \mathrm{mol} / \mathrm{l})$. Liver biopsy showed a cholestatic hepatitis and a cholecystogram was normal. Rifampicin was stopped. Jaundice regressed completely in 2 weeks. The patient was discharged from hospital on streptomycin $0.5 \mathrm{~g}$, isoniazid $300 \mathrm{mg}$ and ethambutol $1.2 \mathrm{~g}(25 \mathrm{mg} / \mathrm{kg})$, pyridoxine $20 \mathrm{mg}$ and metformin $1 \mathrm{~g}$ daily.

Two weeks later, he developed blurring of vision and thereafter he had rapidly progressive vertigo. He was readmitted to hospital. Visual acuity was diminished and colour vision was intact. His gait was extremely unsteady and Rhomberg's sign was positive. Streptomycin and ethambutol were stopped. Para-aminosalicylic acid (PAS), $12 \mathrm{~g} /$ day, was started. Vertigo was controlled with cinnarizine and the patient was discharged.

Two weeks later the patient was readmitted comatose with a marked right-sided hemiparesis but no sweating or tachycardia. The blood glucose concentration was $1.4 \mathrm{mmol} / \mathrm{l}$. He was infused with $25 \mathrm{ml}$ of $50 \%$ glucose following which his coma and hemiparesis resolved promptly. Metformin was stopped. He had considerable nausea and diarrhoea both of which were controlled symptomatically. He had no further hypoglycaemia and blood glucose levels remained normal. He was encouraged to eat regular meals and was discharged from hospital. 
Twenty-four hours later he was readmitted in coma. He had refused to eat following his discharge because of nausea and vomiting. The blood glucose concentration was $2.0 \mathrm{mmol} / \mathrm{l}$. He was infused with glucose and he regained consciousness. On close questioning it was revealed that he had been taking $18 \mathrm{~g}$ of PAS daily. The dose of PAS was reduced to $12 \mathrm{~g} /$ day. He continued to have diarrhoea. The stools were pale, unformed, foul smelling and bulky. A D-xylose absorption test was normal. A Schilling test indicated malabsorption by the ileum of vitamin $\mathbf{B}_{12}$ (excretion of vitamin $\mathrm{B}_{12}$ was $<1 \%$ in $9 \mathrm{hr}$, not altered by intrinsic factor). PAS was stopped. Ethambutol was restarted in a much smaller dose $(12 \mathrm{mg} / \mathrm{kg})$ as his vision had by now returned to normal.

He continued to make steady progress on treatment with isoniazid and ethambutol. The miliary shadows in his chest X-ray have now resolved completely and he has had no further hypoglycaemia or diarrhoea.

\section{Discussion}

In view of his Indian background and diabetes, antituberculous treatment was started in this patient with miliary shadows on his chest X-ray, in spite of the absence of direct bacteriological evidence of tuberculous infection. Tuberculous infection is 4 times as common in diabetic patients as in the normal population (Turner-Warwick, 1957). The fever, cough and sweats subsided within a week.

This case is quite remarkable in that the patient had toxic effects from all antituberculous drugs which were used in his treatment. He developed cholestatic hepatitis following rifampicin and isoniazid, visual blurring following ethambutol, vertigo following streptomycin and diarrhoea with ileal malabsorption following PAS. All of these are known toxic and side effects of the drugs mentioned. Impaired renal function probably predisposed him to the toxic effects since all drugs mentioned above are either wholly or partly excreted via the kidneys.
The 2 episodes of hypoglycaemic coma were, however, entirely unexpected. Metformin was $\stackrel{\varnothing}{\complement}$ stopped after the first episode and is in any case $c$. not known to cause significant hypoglycaemia. $\vec{\Rightarrow}$ Since the patient continued on isoniazid and pyri- $\stackrel{5}{\rightarrow}$ doxine throughout the period of antituberculous $\frac{}{C}$ therapy even after the hypoglycaemic episodes, they $\frac{\bar{\sigma}}{\bar{N}}$ are not likely to have been the cause of hypo- $\frac{\sigma}{\widehat{D}}$

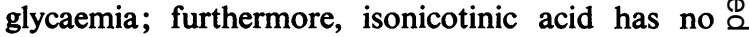
effect upon blood glucose concentrations (Fang क et al., 1968). It therefore seems likely that PAS $\vec{\circ}$ was the cause of hypoglycaemia in this patient. Since PAS is a salicylate derivative, it is probable $\vec{\omega}$ that its effect is exerted through a mechanism similar $\stackrel{\circ}{\circ}$ to that of aspirin. Aspirin can induce a fall in blood 8 glucose concentrations in pancreatectomized anim- 3 . als through an increase in the peripheral uptake of of glucose by tissues with a concomitant suppression 8 of fatty acids release (Fang et al., 1968). The relative $\mathrm{N}$ efficacy of PAS as a hypoglycaemic agent is difficult $\vec{\omega}$ to comment upon but it is of interest that neither $G$ biguanides nor aspirin (even in cases of poisoning) are known to induce hypoglycaemic coma. Indeed, $\vec{\overrightarrow{ }}$ Gilgore and Rupp (1961) have demonstrated that $\mathbb{D}$ intravenous salicylates lower blood glucose concentrations only in hyperglycaemic patients but not in euglycaemic ones. This effect of PAS warrants further investigation.

\section{References}

Fang, V., Foye, W.O., Robinson, S.M. \& Jenkins, H.J. 요 (1968) Hyperglycemic activity and chemical structure of $\varrho$ salicylates. Journal of Pharmaceutical Sciences, 57, $\overrightarrow{\vec{\theta}}$ 2111.

GILGORE, S.G. \& RUPP, J.J. (1961) The response of blood glucose to intravenous salicylate. Metabolism, 10, 419.

REID, J. \& LightBoDY, T.D. (1959) The insulin equivalence of salicylate. British Medical Journal, 1, 897.

Reid, J., Macdougall, A.J. \& ANDrews, M.M. (1957) Aspirin and diabetes mellitus. British Medical Journal, 2, 1071.

TURNer-Warwick, M. (1957) Pulmonary tuberculosis and diabetes mellitus. Quarterly Journal of Medicine, 26, 31. 